\title{
O papel do RDW, da morfologia eritrocitária e de parâmetros plaquetários na diferenciação entre anemias microcíticas e hipocrômicas
}

\author{
The role of $R D W$, erythrocyte morphology and platelet parameters in the differentiation between \\ microcytic and hypochromic anemias
}

Januária F. Matos ${ }^{l}$

Maria das Graças Carvalho ${ }^{2}$

Luci M. S. Dusse ${ }^{2}$

Mônica de F. R. Ferreira ${ }^{3}$

Rachel V. B. Stubbert ${ }^{4}$
As anemias microcíticas e hipocrômicas atingem grande parcela da população mundial. Entre estas, significativa porcentagem de casos se deve à deficiência do ferro, enquanto em algumas regiões a frequência de talassemia menor se torna importante. Por outro lado, a anemia de doença crônica é a causa mais comum de anemia em pacientes hospitalizados. O diagnóstico diferencial destas doenças é clinicamente importante, e é atualmente realizado através dos exames padrão ouro envolvendo a avaliação do metabolismo do ferro e dosagem de $\mathrm{HbA}_{2}$. Embora dotados de grande utilidade, estes testes podem apresentar uma metodologia mais demorada e onerosa que, em casos de concomitância de doenças, comuns na prática clínica, não conseguem proporcionar um correto diagnóstico. Na tentativa de otimizar e direcionar o diagnóstico destas anemias, o uso de alguns parâmetros derivados dos modernos contadores automáticos tem sido sugerido. Neste estudo, o papel do $R D W$, parâmetros plaquetários (número de plaquetas, PDW, VPM) e morfologia eritrocitária como parâmetros diferenciadores, foi avaliado em um grupo de 159 pacientes portadores de anemia microcítica e hipocrômica devido à deficiencia do ferro, anemia de doença crônica e talassemia beta menor, comprovado pelos exames padrão ouro. Foi possivel observar que o RDW não se mostrou um bom discriminante, enquanto o índice plaquetário PDW pode ser um parâmetro auxiliar no diagnóstico diferencial das anemias microcíticas e hipocrômicas. Com relação às alterações morfológicas dos eritrócitos, o pontilhado basófilo foi um achado bastante comum apenas em pacientes portadores de talassemia beta menor, com indicios de potencial utilidade na elucidação de casos de microcitose. Rev. Bras. Hematol. Hemoter. 2008;30(6):463-469.

Palavras-chave: Anemias microciticas e hipocrômicas; parâmetros plaquetários; morfologia eritrocitária; índice de anisocitose eritrocitária.

${ }^{1}$ Professora de Hematologia Clínica/Funcesi (Fundação Comunitária de Ensino Superior de Itabira) - Itabira-MG.

${ }^{2}$ Professora Associada do Departamento de Análises Clínicas e Toxicológicas da Faculdade de Farmácia da UFMG - Belo Horizonte-MG.

${ }^{3}$ Professora de Hematologia Clínica/Instituto Newton Paiva. Coordenadora do Serviço de Patologia Clínica do Hospital

Governador Israel Pinheiro (Ipsemg) - Belo Horizonte-MG.

${ }^{5}$ Farmacêtica Bioquímica do Serviço de Patologia Clínica do Hospital Governador Israel Pinheiro (Ipsemg) - Belo Horizonte-MG.

Universidade Federal de Minas Gerais - Faculdade de Farmácia - Departamento de Análises Clínicas e Toxicológicas - Belo Horizonte-MG.

Correspondência: Maria das Graças Carvalho

Av. Antônio Carlos, 6627 - Pampulha

31270-901 - Belo Horizonte-MG - Brasil

Tel: (+55 31) 3409-6881; Fax: (+55 31) 3409-6895

Email: mgcarvalho@farmacia.ufmg.br 


\section{Introdução}

As anemias microcíticas e hipocrômicas estão entre os tipos mais comuns de anemia encontrados na prática clínica. No nosso meio, a deficiência de ferro (anemia ferropriva), deficiência de cadeias de globina (talassemias) e as doenças crônicas constituem as principais causas de anemias microcíticas e hipocrômicas. ${ }^{1}$

Em virtude da considerável frequência deste tipo de anemia, a sua diferenciação torna-se de grande importância. Atualmente, o protocolo aceito para o diagnóstico de tais doenças inclui os exames padrão ouro, que envolvem a avaliação do metabolismo do ferro e a dosagem de $\mathrm{HbA}_{2}$. Estes testes possuem grande utilidade, contudo requerem uma metodologia mais demorada e onerosa e que, em casos de concomitância de doenças, comuns na prática clínica, não conseguem proporcionar um correto diagnóstico para o paciente.

Com o intuito de reduzir custos e facilitar o diagnóstico destas anemias, vários parâmetros derivados dos modernos contadores automáticos têm sido sugeridos. ${ }^{2,3}$ Um destes, o índice de anisocitose eritrocitária (RDW), consiste em uma medida do grau de variação do tamanho do eritrócito. ${ }^{4}$ É relatado que algumas condições causadoras de microcitose são acompanhadas por uma heterogeneidade do tamanho das hemácias tais como a anemia ferropriva, enquanto outras doenças, como a talassemia menor e a anemia de doença crônica, apresentam homogeneidade da população microcítica, levando a valores de RDW aumentados ou normais, respectivamente. ${ }^{4-7}$

Embora muito se disponha na literatura sobre índices e parâmetros da série eritrocitária na diferenciação das anemias microcíticas e hipocrômicas, poucos são os estudos realizados com o propósito de avaliar o papel dos índices plaquetários como possíveis parâmetros auxiliares na discriminação deste tipo de anemia. É bem conhecido que uma grande variedade de condições clínicas e cirúrgicas pode resultar em um fenômeno de trombocitose reativa, entre elas a anemia ferropriva, doenças inflamatórias, malignidades, infecções e cirurgias. ${ }^{8,9}$

Além dos parâmetros obtidos dos contadores automáticos fazendo parte de uma completa avaliação hematológica de rotina, a minuciosa análise do esfregaço sanguíneo pode ser útil por fornecer indícios quanto à presença de uma determinada doença. Alterações morfológicas, tais como pontilhados basófilos e hemácias em alvo, não estão exclusivamente associadas com uma hemoglobinopatia, entretanto, são achados úteis se, no caso da talassemia, o VCM ou HCM estiverem abaixo dos valores de referência. ${ }^{10}$

Desta forma, o propósito deste trabalho foi avaliar a eficiência do RDW, e o valor dos parâmetros referentes à série plaquetária e morfologia eritrocitária como auxiliares no diagnóstico diferencial das anemias microcíticas e hipocrômicas em nosso meio.

\section{Casuística e Método}

Para a realização deste estudo foram coletadas e avaliadas amostras de 159 pacientes com idade superior a 18 anos atendidos no Serviço de Patologia Clínica do Hospital Governador Israel Pinheiro. Estes pacientes apresentavam valores de hemoglobina inferiores a $12 \mathrm{~g} / \mathrm{dl}$ para mulheres e $13 \mathrm{~g} / \mathrm{dl}$ para homens e, ainda, um VCM inferior a $80 \mathrm{fl}$. A determinação dos parâmetros hematológicos foi realizada no contador automático Advia ${ }^{\circledR} 120$ da Bayer ${ }^{\circledR}$. Com o propósito de classificar o tipo de anemia microcítica e hipocrômica, os níveis de ferro sérico, capacidade total de ligação do ferro à transferrina e a ferritina sérica foram determinados, além da realização da eletroforese de hemoglobina. Os níveis de ferro sérico e a capacidade de ligação do ferro foram obtidos no aparelho Dimension AR ${ }^{\circledR}$, da Dade Behring, por métodos colorimétricos usando-se kits da marca Dade Behring com os seguintes valores de referência: ferro sérico ( 35 a $150 \mu \mathrm{g} / \mathrm{dl})$; capacidade de ligação do ferro $(250$ a $450 \mu \mathrm{g} / \mathrm{dl})$. A concentração de ferritina sérica foi medida no aparelho Immulite ${ }^{\circledR}$ da DPC $®$, que utiliza o método de quimioluminescência e kits Immulite 2000 da DPC ${ }^{\circledR}$ (Diagnostic Products Corporation) cujos valores de referência são 28 a $397 \mathrm{ng} / \mathrm{ml}$ para homens e 6 a $159 \mathrm{ng} / \mathrm{ml}$ em mulheres. A eletroforese de hemoglobina foi realizada usando-se fitas de acetato de celulose, em $\mathrm{pH}$ alcalino, 8,6, em cuba Fonte Eletroforese Tecnow ${ }^{\circledR} 7000$. Em caso de suspeita de aumento de $\mathrm{HbA}_{2}$, foi realizada a sua dosagem pelo método de eluição da fita eletroforética. Baseandose nos resultados destes testes, os pacientes com um quadro de anemia microcítica e hipocrômica foram classificados como portadores de anemia ferropriva quando apresentaram níveis baixos de ferritina (inferiores a $6 \mathrm{ng} / \mathrm{ml}$ e $28 \mathrm{ng} / \mathrm{ml} \mathrm{em}$ mulheres e homens, respectivamente). Os pacientes que apresentaram níveis séricos de ferritina e ferro normais, porém dosagem de hemoglobina $\mathrm{A}_{2}$ aumentada (superior a 3,5 g/dl) foram classificados como portadores de $\beta$ talassemia menor. Um terceiro grupo foi composto de pacientes com anemia microcítica e hipocrômica cujos níveis de ferritina estavam aumentados ou normais (porém sempre acima de $100 \mathrm{ng} / \mathrm{ml}$ ), e capacidade total de ligação do ferro e ferro sérico normais ou diminuídos, os quais, juntamente com dados clínicos, caracterizam um tipo de anemia denominada anemia de doença crônica (ADC). Um nível de ferritina acima de $100 \mathrm{ng} / \mathrm{ml}$, adotado para a classificação dos pacientes no grupo ADC, permitiu a exclusão de possíveis casos de concomitância de ADC e anemia ferropriva, indicando a presença de reserva férrica na medula óssea. Desta forma, 83 pacientes puderam ser classificados como portadores de anemia ferropriva, 53 como portadores de ADC e 23 como $\beta$ talassemia menor. Possíveis casos de $\alpha$ talassemia não puderam ser classificados por meio da eletroforese de hemoglobina, pois, como é sabido, as formas heterozigóticas da doença com uma ou duas deleções somente podem ser confirmadas com certeza por métodos de biologia molecular. Tais pacientes, cuja 
microcitose e hipocromia não se enquadravam em nenhum dos três grupos, foram excluídos da análise estatística.

Foram adotados para o RDW e parâmetros plaquetários os valores de referência do aparelho utilizado (Advia ${ }^{\circledR} 120$ da Bayer $\left.{ }^{\circledR}\right)$, sendo estes: RDW (11,6 a 14,8\%), VPM (8,0 a $10,0 \mathrm{fLl}$ ), PDW (25 a 65\%) e número de plaquetas (150.000 a $400.000 / \mu \mathrm{l})$. Os dados referentes ao RDW e aos parâmetros pertencentes à série plaquetária do hemograma foram submetidos a uma análise estatística utilizando-se o Programa Sigma 2.03 e Prisma 4. A análise de variância (Anova) foi empregada para investigar a presença de diferença significativa entre os grupos. Posteriormente, o teste de Tukey foi aplicado para localizar a diferença no caso dos dados paramétricos. Na comparação de dados não paramétricos, foi utilizado o teste de Kruskal-Wallis seguido da aplicação do teste de Dunn's. Valores de $p<0,01$ foram considerados estatisticamente significativos por serem mais representativos. Além da investigação de parâmetros hematológicos e índices plaquetários, os esfregaços sanguíneos dos pacientes dos três grupos de anemias microcíticas e hipocrômicas foram submetidos a uma minuciosa análise microscópica, buscando possíveis diferenças morfológicas que pudessem auxiliar na diferenciação entre estas. Foi avaliada a presença e a proporção de ovalócitos, dacriócitos, hemácias em alvo, hemácias com pontilhados basófilos e a formação de rouleaux. O critério utilizado para avaliar a formação de rouleaux foi a presença de empilhamento de hemácias em todos os campos ou na maioria destes. A área para a realização da hematoscopia correspondeu àquela próxima à cauda do esfregaço sanguíneo onde normalmente não existe mais sobreposição de hemácias, estando estas apenas justapostas em um esfregaço feito com amostra de sangue normal. A presença das outras alterações foram avaliadas também com base no achado destas em todos os campos/ frequentes campos, com exceção do pontilhado basófilo cujos esfregaços sanguíneos com raros eventos já foram classificados como positivos.

\section{Resultados}

Após a classificação dos pacientes como portadores de anemia ferropriva, $\beta$ talassemia menor ou ADC, estes foram caracterizados segundo os resultados dos parâmetros plaquetários e RDW (Tabela 1). No grupo ADC, composto de 53 pacientes, apenas quatro $(7,5 \%)$ foram atendidos no ambulatório; quarenta $(75,5 \%)$ estavam internados, em tratamento de quimioterapia ou submetendo-se à hemodiálise; e nove $(17,0 \%)$ foram atendidos no serviço médico de urgência.

Através da análise estatística realizada não foi possível observar diferença significativa entre os valores de RDW, número de plaquetas e VPM dos três grupos de anemias. No caso do parâmetro da série plaquetária PDW, foi encontrada diferença significativa do grupo de pacientes portadores de
Tabela 1. Alterações morfológicas dos eritrócitos e número de pacientes com o respectivo valor percentual

\begin{tabular}{cccc}
\hline & AF $(n=83)$ & ADC $(n=53)$ & BTal $(n=23)$ \\
\hline $\begin{array}{c}\text { Pontilhado } \\
\text { basófilo }\end{array}$ & 0 & 0 & $14(60,9 \%)$ \\
Ovalócito & $61(73,5 \%)$ & $43(81,1 \%)$ & $22(95,6 \%)$ \\
Dacriócito & $7(8,4 \%)$ & $7(13,2 \%)$ & $21(91,3 \%)$ \\
Hemácia em alvo & $30(36,1 \%)$ & $27(50,9 \%)$ & $23(100,0 \%)$ \\
Rouleaux & $5(6 \%)$ & $18(34,0 \%)$ & $04(17,4 \%)$ \\
\hline
\end{tabular}

AF - anemia ferropriva, ADC - anemia de doença crônica,

$B$-Tal - $B$ talassemia menor

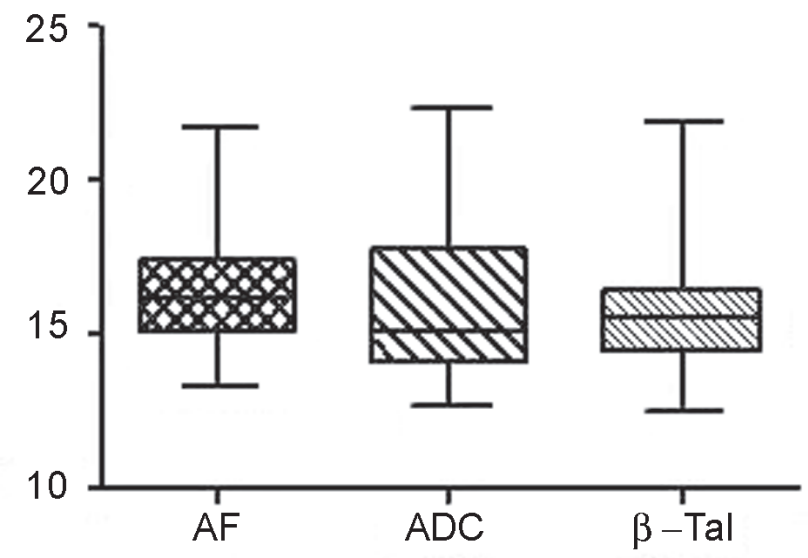

$R D W$ - indice de anisocitose eritrocitária; $A F$ - anemia ferropriva, $A D C$ - anemia de doença crônica; $\beta$-Tal - $\beta$ talassemia menor

Figura 1. Distribuição dos valores de anisocitose eritrocitária (RDW) na anemia ferropriva (AF), na anemia de doença crônica (ADC) e na $ß$ talassemia menor ( $ß-T a l)$. As extremidades de cada box-plot correspondem ao primeiro e terceiro quartis e a linha dentro do box representa a mediana

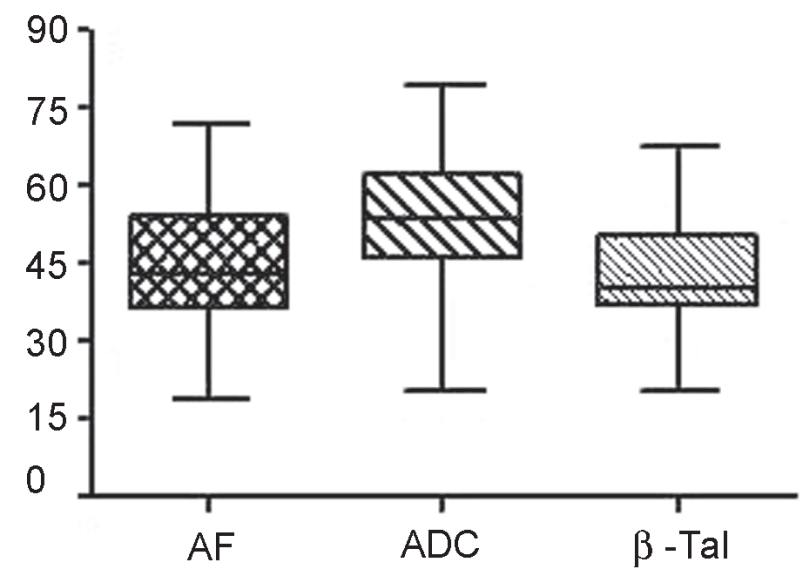

$P D W$ - indice de anisocitose plaquetária; $A F$ - anemia ferropriva, $A D C$ - anemia de doença crônica; $\beta$-Tal - $\beta$ talassemia menor

Figura 2. Distribuição dos valores de anisocitose plaquetária (PDW) na anemia ferropriva (AF), na anemia de doença crônica (ADC) e na $B$ talassemia menor ( $ß-T a l)$ 
ADC em relação aos demais grupos, sendo que o grupo ADC apresentou o maior valor para o PDW.

Com a finalidade de observar a dispersão de valores dos parâmetros RDW e PDW e compará-la entre os três grupos, foram construídos gráficos de box-plot para cada um destes (Figuras 1 e 2).

Para o parâmetro RDW, não foi observada diferença significativa entre as medianas de seus valores nos três grupos de anemias microcíticas e hipocrômicas ao nível de significância de $1 \%(\mathrm{p}=0,042)$. Ocorreu uma grande sobreposição de dados entre todos os três grupos, como mostra $o$ gráfico de box-plot do referido índice.

Em relação à amplitude de distribuição das plaquetas (PDW) observou-se a presença de diferença significativa entre os grupos $\mathrm{ADC} \times \beta-\mathrm{Tal}(\mathrm{p}=0,007)$ e $\mathrm{ADC} \times \mathrm{AF}(\mathrm{p}=0,001)$. A análise feita para o grupo $\mathrm{AF} \times \mathrm{x}$-Tal não mostrou diferença significativa $(\mathrm{p}=0,822)$, o que pode ser visualizado pela grande sobreposição gráfica dos valores dos referidos grupos.

$\mathrm{Na}$ análise dos filmes sanguíneos dos pacientes foi observado que a maior proporção de dacriócitos foi encontrada na $\beta$ talassemia menor, onde 21 pacientes, um percentual de $91,3 \%$, apresentavam dacriócitos em seus esfregaços sanguíneos, enquanto apenas sete pacientes portadores de anemia ferropriva $(8,4 \%)$ e sete pacientes do grupo $\mathrm{ADC}(13,2 \%)$ apresentavam esta forma eritrocitária. De maneira semelhante, a maior proporção de hemácias em alvo foi observada no grupo $\beta$ talassemia menor, onde todos os pacientes apresentavam tais formas; no grupo ADC, este número foi de 27 pacientes $(50,9 \%)$, e no grupo de portadores de anemia ferropriva, 30 pacientes, correspondentes a $36,1 \%$. A formação de rouleaux foi verificada em 18 pacientes (34\%) do grupo ADC, quatro pacientes com $\beta$ talassemia menor $(17,4 \%)$ e cinco portadores de anemia ferropriva $(6,0 \%)$, o que mostra uma proporção notavelmente maior desta alteração no grupo $\mathrm{ADC}$, conforme esperado, considerando as causas que levam a esta anemia. O número de pacientes apresentando ovalócitos em seus esfregaços sanguíneos foi elevado em

\begin{tabular}{|c|c|c|c|}
\hline Parâmetros & $\begin{array}{c}\mathrm{AF} \\
(\mathrm{n}=83)\end{array}$ & $\begin{array}{c}\text { ADC } \\
(n=53)\end{array}$ & $\begin{array}{c}\text { B-Tal } \\
(n=23)\end{array}$ \\
\hline RDW & $\begin{array}{c}16,2 \\
(13,3-21,7)\end{array}$ & $\begin{array}{c}15,1 \\
(12,7-22,3)\end{array}$ & $\begin{array}{c}15,5 \\
(12,5-21,9)\end{array}$ \\
\hline $\begin{array}{l}\text { Plaquetas } \\
10^{3} / \mathrm{ul}\end{array}$ & $\begin{array}{c}320,0 \\
(6,0-730,0)\end{array}$ & $\begin{array}{c}304,0 \\
(53,0-831,0)\end{array}$ & $\begin{array}{c}248,0 \\
(89,0-622,0)\end{array}$ \\
\hline VPM (fl) & $\begin{array}{c}7,7 \\
(6,1-11,1)\end{array}$ & $\begin{array}{c}7,4 \\
(5,5-12,5)\end{array}$ & $\begin{array}{c}7,6 \\
(6,0-10,2)\end{array}$ \\
\hline PDW (\%) & $\begin{array}{c}43,0 \\
(18,9-71,5)\end{array}$ & $\begin{array}{c}53,8 \\
(20,1-79,4)\end{array}$ & $\begin{array}{c}40,3 \\
(20,2-67,4)\end{array}$ \\
\hline
\end{tabular}

RDW - índice de anisocitose eritrocitária; VPM - volume plaquetário médio; PDW - amplitude de distribuição das plaquetas (índice de anisocitose plaquetária); a - diferença significativa com o grupo AF; c - diferença significativa com o grupo ß-Tal todos os grupos. A única alteração presente apenas no grupo da talassemia menor foram as hemácias com pontilhados basófilos. Neste grupo, 14 pacientes $(60,9 \%)$ mostravam tal alteração morfológica (Tabela 2).

\section{Discussão}

Entre os parâmetros sugeridos para a distinção entre as condições que cursam com microcitose encontra-se o RDW, que consta das análises dos contadores automáticos modernos, e que reflete a heterogeneidade de distribuição do tamanho dos eritrócitos. ${ }^{7}$ Como verificado por Bessman \& Feinstein, ${ }^{11}$ os eritrócitos de pacientes $\operatorname{com} \beta$ talassemia menor são mais homogêneos quando comparados aos dos pacientes com anemia ferropriva. Consequentemente, o RDW tende a ser maior na anemia ferropriva do que nas $\beta$ talassemias menores. ${ }^{4,10}$ Além das talassemias, uma microcitose homogênea também pode ser observada nos pacientes com ADC, na qual a presença de anisocitose e poiquilocitose são incomuns. ${ }^{3,7} \mathrm{Na}$ anemia ferropriva, a anisocitose é devida à coexistência de hemácias produzidas na medula óssea durante estágios progressivos de deficiência do ferro, dando lugar a uma população variada de eritrócitos incluindo normocíticos e aqueles progressivamente microcíticos. ${ }^{5}$

Contudo, existem controvérsias sobre a real eficácia do RDW como parâmetro auxiliar na distinção das anemias. Alguns estudos apontam a eficiência do RDW na diferenciação dos estados que cursam com microcitose, sendo observada diferença significativa para o RDW entre os pacientes com anemia ferropriva e $\beta$ talassemia menor ${ }^{6,12}$ enquanto outros trabalhos ${ }^{13-20}$ provaram ser o RDW um índice com pequeno poder discriminatório e contribuição limitada na diferenciação das anemias microcíticas e hipocrômicas. No Brasil, Lima et al,${ }^{21}$ avaliando a utilidade clínica do RDW, verificaram que $90 \%$ dos pacientes com anemia ferropriva e $77 \%$ dos pacientes com $\beta$ talassemia menor foram corretamente identificados usando valores de RDW superiores ou inferiores a $21 \%$, respectivamente. Então, concluiu-se que o RDW poderia ser um método específico e sensível para identificar a anemia ferropriva entre pacientes apresentando um quadro de microcitose; contudo, este parâmetro não seria um bom índice para a identificação da $\beta$ talassemia menor. Desta forma, uma distinção clara entre estes distúrbios não poderia ser feito baseando-se no RDW apenas.

Neste estudo não foram verificadas diferenças estatisticamente significativas para o RDW entre as anemias microcíticas avaliadas, indicando não ser este índice um parâmetro auxiliar eficiente na diferenciação destas anemias.

\section{Plaquetas e índices plaquetários}

Apesar dos numerosos trabalhos sobre os índices eritrocitários na diferenciação dos estados que cursam com microcitose, existem poucos relatos sobre a eficiência dos 
índices plaquetários para tal finalidade. Apenas um estudo realizado por Timuragaoglu et al. ${ }^{22}$ investigou possíveis alterações nos parâmetros plaquetários objetivando a diferenciação entre anemia ferropriva e $\beta$ talassemia menor. Estes pesquisadores observaram diferença significativa para todos os parâmetros plaquetários (número de plaquetas, VPM e PDW) quando o grupo anemia ferropriva e $\beta$ talassemia menor foram comparados, concluindo que tais parâmetros poderiam ser usados na distinção destas anemias.

Neste trabalho não foram encontradas diferenças significativas entre as anemias microcíticas e hipocrômicas considerando o número de plaquetas, o que não está em concordância com a literatura, que relata a ocorrência de um fenômeno de trombocitose reativa em várias condições clínicas e cirúrgicas incluindo a anemia ferropriva, infecções, cirurgias, doenças inflamatórias, malignidades, hemólise ou sangramento agudo, recuperação de uma trombocitopenia, após esplenectomia e na artrite reumatóide. ${ }^{8,9}$

É relatado que, em casos de trombocitose observados comumente em processos infecciosos e inflamatórios, e também na anemia ferropriva, um grande número de plaquetas com pequeno volume é liberado na circulação. ${ }^{8}$ Também na doença inflamatória intestinal em atividade foi observada uma diminuição do VPM e, contrariamente, um aumento deste na insuficiência renal crônica tratada com eritropoetina recombinante humana. ${ }^{23,24}$ Contudo, nenhuma diferença significativa foi observada para o VPM entre as anemias estudadas.

Para o PDW foi verificado um valor maior na ADC se comparado aos demais grupos. Sabe-se, até o momento, que vários fatores hematopoéticos de crescimento, tais como IL-1, IL-3, IL-6, IL-11, EPO e TNF presentes na ADC podem, direta ou indiretamente, estimular a megacariocitopoese, promovendo a proliferação e maturação de megacariócitos que aumentam de tamanho, número e ploidia. ${ }^{25-30}$ Além disso, tem sido proposto que, em algumas patologias, tais como a tuberculose pulmonar, o achado de valores maiores para o PDW pode indicar um fenômeno de trombocitose autônoma, na qual a produção plaquetária aparentemente escapa do processo regulatório normal, refletindo não apenas uma reação de fase aguda. ${ }^{31}$ Talvez este também tenha sido o caso de algum dos pacientes integrantes do grupo ADC.

Observou-se que, dentre os parâmetros plaquetários, apenas o PDW se mostrou um índice auxiliar para distinção da ADC das demais anemias microcíticas.

Análise de esfregaço sanguíneo: aspectos morfológicos

É bem sabido as dificuldades em diferenciar anemia ferropriva e $\beta$ talassemia menor unicamente através da morfologia eritrocitária. ${ }^{32} \mathrm{~A}$ análise dos esfregaços sanguíneos dos pacientes deste trabalho revelou que a microscopia pode fornecer importantes indícios na elucidação da patogênese relacionada à microcitose, embora não consiga, se utilizada de forma isolada, estabelecer a causa desta condi- ção. A presença de pontilhados basófilos, presentes no esfregaço sanguíneo de 14 pacientes portadores de $\beta$ talassemia menor e ausente em todos aqueles com anemia ferropriva e $\mathrm{ADC}$, constitui uma forte evidência da presença da doença em questão, apesar de existir na literatura relato de possível ocorrência de pontilhados basófilos também na anemia ferropriva. ${ }^{33}$ Por outro lado, outras alterações como ovalócitos, dacriócitos, hemácias em alvo e rouleaux se mostraram presentes em todos os grupos e foram consideradas de menor relevância para a diferenciação entre as anemias microcíticas estudadas. Porém, apesar de presentes em todos os grupos, as alterações citadas ocorreram em frequências variadas. Rouleaux foi encontrado em maior proporção na ADC, refletindo, possivelmente, a fisiopatologia do distúrbio que pode levar ao aumento de proteínas plasmáticas de fase aguda como o fibrinogênio e imunoglobulinas. $\mathrm{O}$ achado de dacriócitos e hemácias em alvo foi maior em pacientes com $\beta$ talassemia menor se comparados aos outros grupos, informação esta que no contexto global da avaliação clínica de um paciente apresentando microcitose, pode se mostrar como mais um indício esclarecedor da etiologia da doença. Apesar do grande cuidado na realização da análise microscópica, esta pode ter sido prejudicada pela confecção do esfregaço sanguíneo realizada após a exposição do sangue ao EDTA, embora no prazo máximo de quatro horas após a coleta. A literatura e a experiência prática mostram que, mesmo dentro deste período, a exposição do sangue ao EDTA pode provocar alterações incluindo-se a não visualização de pontilhados basófilos, aparecimento de hemácias crenadas e vacuolização de leucócitos ${ }^{34}$. Flynn et $a l .{ }^{13}$ investigaram as limitações do RDW na avaliação de microcitoses além da presença de hemácias em alvo nos esfregaços sanguíneos dos pacientes do estudo e verificaram que estas se encontravam presentes em 29 dos 97 pacientes com talassemia, representando um percentual de $30 \%$ do grupo e em 12 dos 68 pacientes portadores de anemia ferropriva. Finalmente, estes autores observaram que apenas 49 pacientes (27\%) portadores de microcitose devido a diferentes causas, incluindo a anemia ferropriva, talassemia, outras hemoglobinopatias, doenças crônicas e distúrbios com concomitância de outros exibiam hemácias em alvo nos esfregaços sanguíneos. Apesar de comumente observadas em talassemias, a sensibilidade e a especificidade da presença de hemácias em alvo foram baixas para discriminar entre talassemia e outras microcitoses, valores estes de $30 \%$ e $77 \%$, respectivamente.

Observou-se que embora não seja possível alcançar um diagnóstico conclusivo das anemias microcíticas e hipocrômicas somente pela análise morfológica dos esfregaços sanguíneos, esta acrescenta indícios de potencial utilidade na elucidação de um quadro de microcitose. 


\section{Abstract}

Microcytic and hypochromic anemias affect many people worldwide. A significant percentage of cases are due to iron deficiency, while in certain regions the frequency of thalassemia minor is important. On the other hand, anemia of chronic disease is the most common cause of anemia in hospitalized patients. Differential diagnosis between these anemias, currently established by using gold standard tests involving evaluation of iron metabolism and measurement of $\mathrm{Hb}_{2}$, is of clinical importance. Although very useful, these tests are time consuming and onerous. In cases of concomitant diseases, a common finding in the clinical practice, these tests are unable to provide a correct diagnosis. In an attempt to optimize diagnosis of these anemias, the use of some parameters derived from modern automated blood count analyzers has been suggested. In this study, the role of $R D W$, platelet parameters (platelet number, PDW, MPV) and erythrocyte morphology as differentiating parameters were evaluated in a group of 159 patients diagnosed as carriers of microcytic or hypochromic anemias due to iron deficiency, anemia of chronic disease and $\beta$-thalassemia minor, as confirmed by gold standard tests. The RDW did not prove to be a good discriminator, while the platelet index, $P D W$, may be helpful in the differential diagnosis of microcytic and hypochromic anemias. Regarding the red cell morphologic alterations, basophilic stippling was a quite common finding just in patients with $\beta$ thalassemia minor, suggesting it to be a potential marker for elucidating cases of microcytosis. Rev. Bras. Hematol. Hemoter. 2008;30(6):463-469.

Key words: Microcytic and hypochromic anemias; platelet parameters; erythrocyte morphology; red cell distribution width.

\section{Referências Bibliográficas}

1. Oliveira RAG, Neto AP. Anemias e Leucemias - Conceitos Básicos e Diagnóstico por técnicas laboratoriais. São Paulo: Roca, 2004. $421 \mathrm{p}$.

2. Melo MR, Purini MC, Cançado RD, Kooro F, Chiattone CS. Uso de índices hematimétricos no diagnóstico diferencial de anemias microcíticas: uma abordagem a ser adotada? Rev Assoc Med Bras. 2002;48(3):222-4.

3. Bessman JD, Gilmer PR Jr, Gardner FH. Improved classification of anemias by MCV and RDW. Am J Clin Pathol. 1983;80(3):322-6.

4. Clarke GM, Higgins TN. Laboratory investigation of hemoglobinopathies and thalassemias: review and update. Clin Chem. 2000;46(8 Pt 2):1284-90.

5. Green R, King R. A new red cell discriminant incorporating volume dispersion for differentiating iron deficiency anemia from thalassemia minor. Blood Cells. 1989;15(3):481-91.

6. Aslan D, Gümrük F, Gürgey A, Altay C. Importance of RDW value in differential diagnosis of hypochrome anemias. Am J Hematol. 2002;69(1):31-3.

7. Karnad A, Poskitt TR. The automated complete blood cell count. Use of the red blood cell volume distribution width and mean platelet volume in evaluating anemia and thrombocytopenia. Arch Intern Med. 1985;145(7):1270-2.

8. Giles C. The platelet count and mean platelet volume. Br J Haematol. 1981;48(1):31-7.
9. Dan K. Thrombocytosis in iron deficiency anemia. Intern Med. 2005;44(10):1025-6.

10. Trent RJ. Diagnosis of the haemoglobinopathies. Clin Biochem Rev. 2006;27(1):27-38.

11. Bessman JD, Feinstein DI. Quantitative anisocytosis as a discriminant between iron deficiency and thalassemia minor. Blood. 1979;53(2):288-93.

12. Yermiahu T, Ben-Shalom M, Porath A, Vardi H, Boantza A, Mazor $\mathrm{D}$ et al. Quantitative determinations of microcytic-hypochromic red blood cell population and glycerol permeability in irondeficiency anemia and beta thalassemia minor. Ann Hematol. 1999;78(10):468-71.

13. Flynn MM, Reppun TS, Bhagavan NV. Limitations of red blood cell distribution width (RDW) in evaluation of microcytosis. Am J Clin Pathol. 1986;85(4):445-9.

14. Eldibany MM, Totonchi KF, Joseph NJ, Rhone D. Usefulness of certain red blood cell indices in diagnosing and differentiating thalassemia trait from iron-deficiency anemia. Am J Clin Pathol. 1999;111(5):676-82.

15. Alfadhli SM, Al-Awadhi AM, AlKhaldi D. Validity assessment of nine discriminant functions used for the differentiation between iron deficiency anemia and thalassemia minor. J Trop Pediatr. 2007;53(2):93-7.

16. Ntaios G, Chatzinikolaou A, Saouli Z, Girtovitis F, Tsapanidou M, Kaiafa $\mathrm{G}$ et al. Discrimination indices as screening tests for betathalassemic trait. Ann Hematol. 2007;86(7):487-91.

17. Beyan C, Kaptan K, Ifran A. Predictive value of discrimination indices in differential diagnosis of iron deficiency anemia and beta-thalassemia trait. Eur J Haematol. 2007;78(6):524-6.

18. Lafferty JD, Crowther MA, Ali MA, Levine M. The evaluation of various mathematical $\mathrm{RBC}$ indices and their efficacy in discriminating between thalassemic and non-thalassemic microcytosis. Am J Clin Pathol. 1996;106(2):201-5.

19. Tillyer ML, Tillyer CR. Use of red cell distribution width and erythrocyte zinc protoporphyrin in differential diagnosis of $\alpha$ and $\beta$ thalassaemia and iron deficiency. J Clin Pathol. 1994; 47(3):205-8

20. Demir A, Yarali N, Fisgin T, Duru F, Kara A. Most reliable índices in differentiation between thalassemia trait and iron deficiency anemia. Pediatr Int. 2002;44(6):612-6.

21. Lima CS, Reis AR, Grotto HZ, Saad ST, Costa FF. Comparison of red cell distribution width and a red cell discriminant function incorporating volume dispersion for distinguishing iron deficiency from beta thalassemia trait in patients with microcytosis. Sao Paulo Med J. 1996;114(5):1265-9.

22. Timuragaoglu A, Coban E, Erbasan F. The importance of platelet indexes in discriminating between beta-thalassemia trait and iron deficiency anemia. Haematol. 2004;111(4):235-6.

23. Sharpe PC, Desai ZR, Morris TC. Increase in mean platelet volume in patients with chronic renal failure treated with erythropoietin. J Clin Pathol. 1994;47(2):159-61.

24. Kapsoritakis AN, Koukourakis MI, Sfiridaki A, Potamianos SP, Kosmadaki MG, Koutroubakis IE et al. Mean platelet volume: a useful marker of inflammatory bowel disease activity. Am J Gastroenterol. 2001;96(3):776-81.

25. Ishibashi T, Koziol JA, Burstein SA. Human recombinant erythropoietin promotes differentiation of murine megakaryocytes in vitro. J Clin Invest. 1987;79(1):286-9.

26. Carrington PA, Hill RJ, Stenberg PE, Levin J, Corash L, Schreurs $\mathrm{J}$ et al. Multiple in vivo effects of interleukin-3 and interleukin-6 on murine megakaryocytopoiesis. Blood. 1991; 77(1):34-41. 
27. Hill RJ, Warren MK, Stenberg P, Levin J, Corash L, Drummond R et al. Stimulation of megakaryocytopoiesis in mice by human recombinant interleukin-6. Stimulation of megakaryocytopoiesis in mice by human recombinant interleukin-6. Blood. 1991;77 (1):42-8.

28. Teramura M, Kobayashi S, Hoshino S, Oshimi K, Mizoguchi H. Interleukin-11 enhances human megakaryocytopoiesis in vitro. Blood. 1992;79(2):327-31.

29. Dan K, Gomi S, Inokuchi K, Ogata K, Yamada T, Ohki I et al. Effects of interleukin-1 and tumor necrosis factor on megakaryocytopoiesis: mechanism of reactive thrombocytosis. Acta Haematol. 1995;93(2-4):67-72.

30. Kaushansky K. Thrombopoietin. N Engl J Med. 1998;339 (11):746-54.

31. Tozkoparan E, Deniz O, Ucar E, Bilgic H, Ekiz K. Changes in platelet count and indices in pulmonary tuberculosis. Clin Chem Lab Med. 2007;45(8):1009-13.

32. England JM, Fraser PM. Differentiation of iron deficiency from thalassaemia trait by routine blood-count. Lancet. 1973;1 (7801):449-52.

33. Cavaliere TA. Red blood cell indices: implications for practice. Newborn Infant Nurs Rev. 2004;4(4):231-9.

34. Failace RF. Hemograma: manual de interpretação. $4^{\mathrm{a}}$ ed. Porto Alegre: Artmed, 2003. 298p.

Avaliação: Editor e dois revisores externos

Conflito de interesse: não declarado

Recebido: 20/04/2008

Aceito após modificações: 29/08/2008 